\title{
Clinical presentation of tuberculosis: a nine-year single-center experience
}

\author{
Ahmet Cemal Pazarlıํㅜ, Timur Ekiz², Mehmet Akif Abakay \\ ${ }^{1}$ Department of Pulmonary Diseases, Gaziosmanpaşa University School of Medicine, Tokat, Turkey \\ ${ }^{2}$ Department of Physical Medicine and Rehabilitation, Elbistan State Hospital, Kahramanmaraş, Turkey \\ ${ }^{3}$ Department of Otorhinolaryngology, Elbistan State Hospital, Kahramanmaraş, Turkey
}

\begin{abstract}
Objective. The aim of this study was to determine the clinical presentation of tuberculosis cases from our center for the last nine years. Methods. This study was set as descriptive and retrospective. The data was obtained from the hospital records. Subjects who had been diagnosed as tuberculosis and received treatment in our center between the years 2007 and 2015 were included. The cases were classified as newly diagnosed, relapse, transferred, and returning after default. Results. There were 276 (171 males and 105 females) patients with a mean age of $41.5 \pm 19.2$ years. Pulmonary involvement is the most common presentation and seen in 155 $(56.2 \%)$ patients. Lymph node and pleura are the most common extrapulmonary involvements those are seen in $53(19.2 \%)$ and $23(8.3 \%)$ patients, respectively. Number of the cases seems to decreased after 2012. Most $(85.1 \%)$ of the patients were newly diagnosed. Among the subjects, $55.2 \%$ of them had bacteriologic diagnosis, $35.1 \%$ had histopathologic diagnosis. Two subjects died during the treatment period whereas 274 of them completed the treatment program. Conclusions. Our results show that tuberculosis is seen mainly in the adult age group. While pulmonary involvement is the most common presentation, lymph node and pleura involvements are the most common extrapulmonary presentations. Number of the tuberculosis seems to decrease for the recent years. Strict preventive measures and treatment strategies should be administered.
\end{abstract}

Eur Res J 2018;4(3):211-214

Keywords: Tuberculosis, pulmonary involvement, Mycobacterium tuberculosis, extrathoracic tuberculosis, lymphadenitis, treatment strategy.

\section{Introduction}

Tuberculosis still remains a considerable health problem in spite of the strict preventive measures and treatment strategies [1]. Previous studies have already reported the clinical and demographical features, and management of tuberculosis in detail [2-5]. However, recent studies focused on the increased incidence of tuberculosis in the recent years [4-7]. Therefore, the aim of this study was to determine the clinical presentation of tuberculosis cases from our center for the last nine years. 


\section{Methods}

This study was designed as descriptive and retrospectively. The data were obtained from the hospital records. Subjects previously diagnosed with tuberculosis and received treatment in our center (Elbistan, Turkey) between the years 2007 and 2015 were included. Subjects with missing data regarding the diagnosis and clinical involvement, and transferred to other clinics for their treatments were excluded. Age, gender, year, tuberculosis involvement (thoracic, lymph node, pleura, bone, etc.), and diagnostic method (histopathological, microbiological) have been noted. The cases were classified as newly diagnosed, relapse, transferred, and returning after default. This study protocol was approved by the local ethics committee.

\section{Statistical Analysis}

SPSS version 16 (SPSS Inc., Chicago, IL, USA) was used for the statistical analyses. Data were expressed as mean \pm standard deviation or percentage. Chi Square test was used to compare categorical variables between the groups. A $p$ value of 0.05 was set as significance.

\section{Results}

A total of 276 (171 males and 105 females) patients with a mean age of $41.5 \pm 19.2$ years were included in this study. Clinical and demographical features are shown in Table 1. Pulmonary and extrapulmonary involvements are shown in Tables 2 and 3. Pulmonary involvement is the most common presentation, and seen in $155(56.2 \%)$ patients. Lymph node and pleura are the most common extrapulmonary involvements those are seen in $53(19.2 \%)$ and 23 $(8.3 \%)$ patients, respectively.

Table 1. Clinical and demographical features

\begin{tabular}{lc}
\hline Variable & Data $(\mathbf{n}=\mathbf{2 7 6})$ \\
\hline Age (years) & $41.5 \pm 19.2$ \\
Gender & \\
$\quad$ Male & $171(62 \%)$ \\
$\quad$ Female & $105(38 \%)$ \\
Age Group & \\
$\quad$ Adult (18-64) & $218(79 \%)$ \\
$\quad$ Geriatric $(\mathbf{6 5} \geq)$ & $36(13 \%)$ \\
$\quad$ Pediatric $(<\mathbf{1 8})$ & $22(8 \%)$ \\
Pulmonary & $155(56.2 \%$ \\
Extrapulmonary & $108(39.1 \%)$ \\
Both & $13(4.7 \%)$ \\
\hline
\end{tabular}

Table 2. Pulmonary and extrapulmonary involvements

\begin{tabular}{lcccc}
\hline Involvement & Adult (n= 218) & Geriatric $(\mathbf{n}=\mathbf{3 6})$ & Pediatric (n= 22) & Total (n= 276) \\
\hline Pulmonary & 123 & 18 & 14 & $155(56.2 \%)$ \\
Lymph node & 38 & 11 & 4 & $53(19.2 \%)$ \\
Pleura & 20 & 1 & 2 & $23(8.3 \%)$ \\
Bone & 10 & 1 & 0 & $11(4 \%)$ \\
Urinary & 6 & 2 & 0 & $8(2.9 \%)$ \\
Periton & 5 & 0 & 0 & $5(1.8 \%)$ \\
Miliary & 4 & 0 & 0 & $4(1.4 \%)$ \\
Gastrointestinal & 2 & 1 & 1 & $4(1.4 \%)$ \\
Skin & 3 & 1 & 0 & $4(1.4 \%)$ \\
Central Nervous System & 3 & 0 & 0 & $3(1.1 \%)$ \\
Pericardium & 2 & 0 & 1 & $3(1.1 \%)$ \\
Breast & 2 & 1 & 0 & $3(1.1 \%)$ \\
\hline
\end{tabular}

Table 3. Pulmonary and extrapulmonary involvements

\begin{tabular}{lccccc}
\hline Involvement & Adult $(\mathbf{n}=\mathbf{2 1 8})$ & Geriatric $(\mathbf{n}=\mathbf{3 6})$ & Pediatric $(\mathbf{n}=\mathbf{2 2})$ & Total $(\mathbf{n}=\mathbf{2 7 6})$ & $\boldsymbol{p}$ value \\
\hline Pulmonary & $123(56.4 \%)$ & $18(50 \%)$ & $14(63.6 \%)$ & $155(56.2 \%)$ & $p>0.05$ \\
Extrapulmonary & $84(38.5 \%)$ & $17(47.2 \%)$ & $7(31.8 \%)$ & $108(39.1 \%)$ & $p>0.05$ \\
Both & $11(5.1 \%)$ & $1(2.8 \%)$ & $1(4.6 \%)$ & $13(4.7 \%)$ & $p>0.05$ \\
\hline
\end{tabular}

Table 4. Classification of the cases according to the diagnosis

\begin{tabular}{lcccc}
\hline & Adult $(\mathbf{n}=\mathbf{2 1 8})$ & Geriatric $(\mathbf{n}=\mathbf{3 6})$ & Pediatric $(\mathbf{n}=\mathbf{2 2})$ & Total $(\mathbf{n}=\mathbf{2 7 6})$ \\
\hline Newly Diagnosed & $186(85.3 \%)$ & $28(77.8 \%)$ & $21(95.5 \%)$ & $235(85.1 \%)$ \\
Relapse & $18(8.3 \%)$ & $4(11.1 \%)$ & $1(4.5 \%)$ & $23(8.3 \%)$ \\
Returning after default & $3(1.3 \%)$ & $0(0 \%)$ & $0(0 \%)$ & $3(1.1 \%)$ \\
Transferred in & $11(5.1 \%)$ & $4(11.1 \%)$ & $0(0 \%)$ & $15(5.4 \%)$ \\
\hline
\end{tabular}


Number of tuberculosis patients over the years is shown in Figure 1. Presentation of pulmonary and extrapulmonary involvements over the years is shown in Figure 2. Number of the cases seems to be decreasing after 2012.

Classification of the cases according to the diagnosis is shown in Table 4. Most $(85.1 \%)$ of the patients were newly diagnosed. Diagnosis method is shown in Table 5. Among the subjects, while 55.2\% of them had bacteriologic diagnosis, 35.1\% had histopathologic diagnosis. Two subjects died during the treatment period whereas 274 of them completed the treatment program.

Table 5. Diagnosis method

\begin{tabular}{lc}
\hline Diagnosis & Data $(\mathbf{n}=\mathbf{2 7 6})$ \\
\hline Bacteriologic & $144(52.2 \%)$ \\
Histopathologic & $97(35.1 \%)$ \\
Quantiferon & $2(0.7 \%)$ \\
Missing data & $33(12 \%)$ \\
\hline
\end{tabular}

\section{Discussion}

Tuberculosis is an infectious disease caused by Mycobacterium tuberculosis. Although tuberculosis primarily involves the lungs, any sort of extrapulmonary involvements can be seen [8-13]. Recording, analysis, and reporting the tuberculosis cases is the mainstay of the tuberculosis control program according to the WHO. As such, there is standard data set of special tuberculosis surveillance conducted in the European Region, likewise in our county [7]. In this context, we aimed to define our tuberculosis cases in our center.

The data related to tuberculosis in our county has

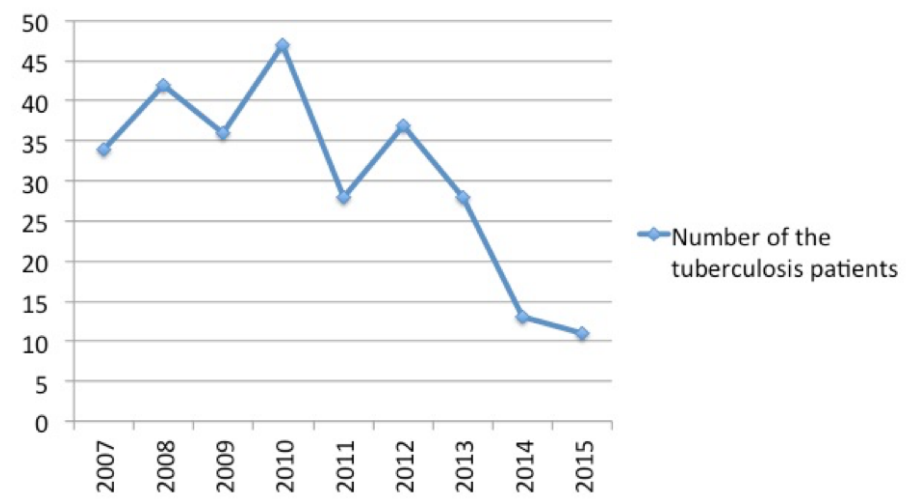

Figure 1. The number of tuberculosis patients over the years. been recruited individually according to WHO definitions since 2005. Furthermore, directly observed treatment strategy was announced in 2006. These two facts resulted in achieving more reliable data thereafter [14]. We have described the clinical involvement of tuberculosis and our results showed that most of the patients were adults $(n=123)$ followed by geriatric $(n$ $=18)$ and pediatric $(n=13)$ patients. Among 276 cases, $56.2 \%$ of them had pulmonary tuberculosis whereas $39.2 \%(n=108)$ had extrapulmonary involvements. In addition, $4.7 \%(\mathrm{n}=13)$ had both pulmonary and extrapulmonary tuberculosis. When compared the pulmonary and extrapulmonary involvements between the age groups, no significant difference was observed $(p>0.05)$. Up to $40 \%$ of extrapulmonary $\mathrm{TB}$ cases are attributable to tuberculous lymphadenitis [15]. Accounting for roughly $4 \%$ of all TB cases, pleural TB is the second leading cause of extrapulmonary TB [16].

As for the extrapulmonary tuberculosis in our study; lymph node involvement $(19.2 \%)$ is the most common presentatin followed by the pleura $(8.3 \%)$ and bone (4\%). Previous studies reported the extrapulmonary tuberculosis rate in different populations [13,17-20]. Compared with them, extrapulmonary tuberculosis rate was higher in our study population. However, our results were consistent with the study done by İnönü et al. [20], and government statistics in our country. While absolute numbers have been on the rise, the prevalence of tuberculosis in relationship to population has trended downward during the past 15 years, and global public health efforts have averted an estimated 6 million deaths during this time [2]. On contrast, a decrease was observed in tuberculosis patients in our study population after 2012 .

When classified the groups according to the

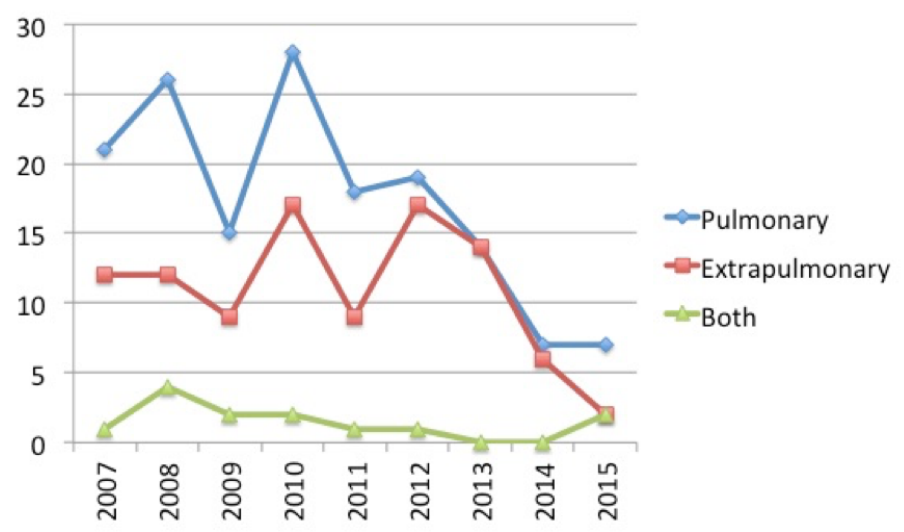

Figure 2. The number of pulmonary and extrapulmonary tuberculosis patients over the years. 
diagnosis, most of them were newly diagnosed $(85.1 \%)$ while relapse were seen in $(8.3 \%)$ patients. Approximately $5 \%$ of the patients were transferred in our center and $1.1 \%$ was returning after default. Regarding the number of the relapse according to the age groups; although relapse rate was higher in the geriatric group, it did not reach significance. Overall, we herein imply that a possible relapse should be considered in all age groups.

Bacteriologic diagnosis is vital for the early diagnosis and directly observed treatment strategy. This fact will decrease the incidence of tuberculosis in the community. In our study, $55.2 \%$ of the subjects were diagnosed with tuberculosis according to the bacteriologic tests, and $35.1 \%$ of them according to the histopathological examination. Only two patients were diagnosed with tuberculosis with quantiferon test. However, there is missing data in twelve percent.

\section{Limitations}

We have some important drawbacks to the current study. First, our study was conducted as retrospectively. Second, this study lacks several comorbidities such as diabetes mellitus, immunosuppression, malnutrition, and malignancy those might be important for the infection of tuberculosis. Last, aside from the clinical involvement, treatment time, drug resistance, side affects were not mentioned in our study.

\section{Conclusions}

In the light of our results, tuberculosis is seen mainly in the adult age group. While pulmonary involvement is the most common presentation in all age group, lymph node and pleura involvements are the most common extrapulmonary presentations. Number of the tuberculosis seems to decrease for the recent years.

\section{Conflict of interest}

The authors disclosed no conflict of interest during the preparation or publication of this manuscript.

\section{Financing}

The authors disclosed that they did not receive any grant during conduction or writing of this study.

\section{References}

[1] Sia IG, Wieland ML. Current Concepts in the Management of Tuberculosis. Mayo Clin Proc 2011;86:348-61.

[2] Lonnroth K, Castro KG, Chakaya JM, Chauhan LS, Floyd K, Glaziou P, et al. Tuberculosis control and elimination 2010-50: cure, care, and social development. Lancet 2010;375:1814-29.

[3] Getahun H, Matteelli A, Abubakar I, et al. Management of latent Mycobacterium tuberculosis infection: WHO guidelines for low tuberculosis burden countries. Eur Respir J 2015;46:1563-76.

[4] Lönnroth K, Migliori GB, Raviglione M. Toward tuberculosis elimination in low-incidence countries: reflections from a global consultation. Ann Intern Med 2014;161:670-1.

[5] Lienhardt C, Glaziou P, Uplekar M, Lönnroth K, Getahun H, Raviglione M. Global tuberculosis control: lessons learnt and future prospects. Nat Rev Microbiol 2012;10:407-16.

[6] Coskun O, Safaz I, Gul CH, Ozgul A, Eyigun CP. Heterotopic ossification in a patient with tuberculous meningoencephalitis. Intern Med 2008;47:2195-6.

[7] World Health Organization. Global Tuberculosis Control: Epidemiology, Strategy, Financing: WHO Report 2009. Geneva, Switzerland: World Health Organization; 2009.

[8] Liao JR, Zhang D, Wu XL. Pulmonary tuberculosis combined with hepatic tuberculosis: a case report and literature review. Clin Respir J 2015;9:501-5.

[9] Pefura-Yone EW, Kuaban C, Assamba-Mpom SA, Moifo B, Kengne AP. Derivation, validation and comparative performance of a simplified chest X-ray score for assessing the severity and outcome of pulmonary tuberculosis. Clin Respir J 2015;9:157-64.

[10] Christopoulos A, Saif MW, Sarris EG, Syrigos KN. Epidemiology of active tuberculosis in lung cancer patients: a systematic review. Clin Respir J 2014;8:375-81.

[11] Flor de Lima B, Tavares M. Risk factors for extensively drugresistant tuberculosis: a review. Clin Respir J 2014;8:11-23.

[12] Hassan WA, Darwish AM. Impact of pulmonary tuberculosis on menstrual pattern and fertility. Clin Respir J 2010;4:157-61.

[13] Kamper-Jorgensen Z, Lillebaek T, Andersen AB. Occupational tuberculosis following extremely short exposure. Clin Respir J 2009;3:55-7.

[14] Türk Tabipleri Birliğ Tuiberkuiloz Raporu. Türk Tabipleri Birliğ Yayınları. Birinci Bask1, Ocak 2012, Ankara.

[15] Peto HM, Pratt RH, Harrington TA, LoBue PA, Armstrong LR. Epidemiology of extrapulmonary tuberculosis in the United States, 1993-2006. Clin Infect Dis. 2009;49:1350-7.

[16] Baumann MH, Nolan R, Petrini M, Lee YC, Light RW, Schneider E. Pleural tuberculosis in the United States: incidence and drug resistance. Chest 2007;131:1125-32.

[17] Rowińska-Zakrzewska E, Korzeniewska-Koseła M, RoszkowskiŚliż K. Extrapulmonary tuberculosis in Poland in the years 1974-2010. Pneumonol Alergol Pol 2013;81:121-9.

[18] Kulchavenya E. Extrapulmonary tuberculosis: are statistical reports accurate? Ther Adv Infect Dis 2014;2:61-70.

[19] Lee JY. Diagnosis and treatment of extrapulmonary tuberculosis. Tuberc Respir Dis (Seoul) 2015;78:47-55.

[20] İnönü H, Köseoğlu D, Pazarlı C, Yılmaz A, Doruk S, Yenisehirli $\mathrm{G}$, et al. [The characteristics of cases with extrapulmonary tuberculosis in a university hospital]. Tur Toraks Der 2010;11:167-73. [Article in Turkish] 